Article

\title{
Cu-BTC Metal-Organic Framework Modified Membranes for Landfill Leachate Treatment
}

\author{
Mahfar Mazani ${ }^{1}$, Sadegh Aghapour Aktij ${ }^{2,3}$, , Ahmad Rahimpour ${ }^{1, *}$ and \\ Naser Tavajohi Hassan Kiadeh ${ }^{4}$ \\ 1 Department of Chemical Engineering, Babol Noshirvani University of Technology, Shariati Avenue, Babol, \\ Mazandaran 4714871167, Iran; mahfar.mazani@gmail.com \\ 2 Department of Mechanical Engineering, 10-367 Donadeo Innovation Center for Engineering, Advanced \\ Water Research Lab (AWRL), University of Alberta, Edmonton, AB T6G 1H9, Canada; aghapour@ualberta.ca \\ 3 Department of Chemical \& Materials Engineering, University of Alberta, Edmonton, AB T6G 1H9, Canada \\ 4 Department of Chemistry, Chemical-Biology Centre, Technical Chemistry, Umeå University, SE-90787 Umeå, \\ Sweden; naser.tavajohi@umu.se \\ * Correspondence: ahmadrahimpour@nit.ac.ir; Tel.: +98-11-32334204
}

Received: 1 December 2019; Accepted: 24 December 2019; Published: 26 December 2019

\begin{abstract}
In this study, Cu-BTC (copper(II) benzene-1,3,5-tricarboxylate) metal-organic frameworks (MOFs) were incorporated into the structure of polysulfone (PSf) ultrafiltration (UF) membranes to improve the membrane performance for landfill leachate treatment, whereby different concentrations of Cu-BTC $(0.5,1,1.5,2 \mathrm{wt} \%)$ were added to the PSf casting solution. The successful incorporation of $\mathrm{Cu}$-BTC MOFs into the modified membranes was investigated by field emission scanning electron microscopy (FE-SEM) and energy dispersive X-ray (EDX). The Cu-BTC-modified PSf membranes showed higher performance in terms of flux and rejection, as compared to the neat PSf membrane. For example, the pure water flux (PWF) of neat membrane increased from 111 to $194 \mathrm{~L} / \mathrm{m}^{2} \mathrm{~h}(\mathrm{LMH})$ by loading $2 \mathrm{wt} \% \mathrm{Cu}$-BTC into the membrane structure, indicating $74 \%$ improvement in PWF. Furthermore, the flux of this membrane during filtration of landfill leachate increased up to $15 \mathrm{LMH}$, which indicated $50 \%$ improvement in permeability, as compared to the neat membrane. Finally, the modified membranes showed reasonable antifouling and anti-biofouling properties than the blank membrane.
\end{abstract}

Keywords: ultrafiltration; polysulfone membrane; MOFs; landfill leachate treatment

\section{Introduction}

Membrane process offers significant potential for separation and purification [1]. Compared to conventional separation methods, membrane separation has significant advantages, such as being energy saving, and having high purification, simplicity of operation, superior efficiency, low operation cost, smaller footprint, better effluent quality and low secondary pollution [2-5]. Therefore, effective separation can be achieved by the membrane process [6,7]. Ultrafiltration (UF), one of the pressure-driven separation processes, has experienced rapid growth in recent decades in treatment of water and wastewater [8-10]. The characteristics of UF membrane performance depend on different factors, including the polymer, the solvent and the non-solvent types, and the composition of the casting solution, etc., [11]. The UF membrane with high water permeability, high rejection capacity, and suitable antifouling property, has been the goal of researchers in UF membrane separation processes [12]. Among various modification methods, such as the use of additives, chemical treatments, coatings and grafting components, the usage of additives is the most common, easy and effective strategy for improving these properties $[13,14]$. A variety of organic and inorganic materials such as $\mathrm{TiO}_{2}[15-17]$, 
$\mathrm{SiO}_{2}[18,19], \mathrm{GO}[20,21]$, etc., have been added into casting solutions to improve the performance of the UF membranes. The selection of additives is very important as the overall performance of the modified membranes exactly rely on it.

Metal-organic frameworks (MOFs) are a group of crystalline porous materials made up of metal ions with organic linkers via strong molecular bonds that have highly tunable structures, by applying diverse metal centers or altering the organic ligand [22,23]. Applying MOFs have gained great academic interest in water treatment technologies in recent years [22-24]. Compared with traditional inorganic materials, MOFs have significant characteristics, such as high surface area and highly ordered pore structure, high pore volume, abundant active sites that provide various specific applications $[18,25]$. Among all applications, MOF materials provide new opportunities in liquid and gas separation processes. Using MOFs in membrane production for liquid separation and water treatment is still in its emerging stage in comparison with its applications for gas separation [26]. MOFs-based membranes have already shown some interesting results in the separation of heavy metal ions $[27,28]$ and organic pollutants [29] from aqueous phases and have attracted great attention in separation technologies. MOFs are combined with membranes in various methods to modify their overall performance [30-32]. Among all these methods, the blending of a MOF into the casting solution has been mostly reported on [24,33]. Prince et al. [34] fabricated a novel membrane with self-cleaning and anti-biofouling surface by blending highly hydrophilic MOF in the polymer solution. The modified membrane indicated a lower flux drop and lower contact angle relative to the control membrane. Arcadio Sotto et al. [35] synthesized UF membranes using MOF and ZnO particles as fillers. MOF-PES membrane exhibited higher pure water flux and BSA rejections than the ZnO-PES membrane. The addition of the fillers would enhance the hydrophilic feature of the PES and PSf membranes, which would exhibit higher water fluxes than the neat membrane. Therefore, there is a great potential for MOFs to replace with traditional inorganic fillers to improve membrane performance [28]. In this work, the influence of the MOF content on the morphology and performance of PSf UF membranes for landfill leachate treatment has been studied. Performance of modified membranes was examined in terms of the water flux, landfill leachate flux (LLF), chemical oxygen demand (COD) removal and natural organic matters (NOM) removal of the landfill leachate. The fouling and bio-fouling potential of membranes were also evaluated using sodium alginate as organic foulant agent, and Escherichia coli (E. coli) suspensions as bio-foulant agent.

\section{Materials and Methods}

\subsection{Materials}

Polysulfone (PSf, $\mathrm{Mw}=35,000 \mathrm{~g} / \mathrm{mol}$, Solvay, Brussels, Belgium) as the base polymer, 1-Methyl-2pyrrolidone (NMP, 99.5\%, Merck, Kenilworth, NJ, USA) as the solvent, Triton x-100 (Merck) as surfactants and polyethyleneglycol (PEG, $\mathrm{Mw}=600 \mathrm{Da}$, Merck) as the pore former were all combined to prepare the casting solution. sodium dodecyl sulfate (SDS, Merck) used into coagulation bath. Escherichia coli (E. coli, ATCC 1399), sodium alginate (Sigma-Aldrich, St. Louis, MS, USA), calcium chloride $\left(\mathrm{CaCl}_{2}\right.$, Merck), sodium chloride $\left(\mathrm{NaCl}, 99.5 \%\right.$, Merck), sodium bicarbonate $\left(\mathrm{NaHCO}_{3}\right.$, Merck), magnesium sulfate ( $\mathrm{MgSO} 4$, Merck), ammonium chloride ( $\mathrm{NH} 4 \mathrm{Cl}$, Merck), potassium phosphate $\left(\mathrm{KH}_{2} \mathrm{PO} 4\right.$, Merck), used to prepare wastewater effluents. $\mathrm{N}, \mathrm{N}$-dimethylformamide (DMF), 1,3,5-benzenetricarboxylic acid $\left(\mathrm{H}_{3} \mathrm{BTC}\right)$, copper(II) nitrate trihydrate and ethanol were obtained from Merck, Germany and used for synthesizing the Cu-BTC (copper(II) benzene-1,3,5-tricarboxylate) MOF. Landfill leachate samples with COD of 18,000 mg/L and $\mathrm{pH}$ of approximately 7 were provided from a municipal leachate site at Ghaemshahr, Iran. The samples were kept at $4{ }^{\circ} \mathrm{C}$ to avoid property variation of the initial leachate, while the COD of landfill leachate was diluted to $4000 \mathrm{mg} / \mathrm{L}$ before use. 


\subsection{Synthesis of $C u-B T C M O F$}

Cu-BTC MOF was synthesized according to the method explained by the authors of [36]. Briefly, 1, 3, 5-benzenetricarboxylic acid ( $\left.1 \mathrm{~g}, \mathrm{H}_{3} \mathrm{BTC}\right)$ and copper(II) nitrate trihydrate (1.5 g) were dissolved in $100 \mathrm{~mL}$ of dimethylformamide (DMF) as a solvent and the resulting mixture was placed in an ultrasonic bath for $30 \mathrm{~min}$. The mixture was placed in an oil bath under reflux conditions at $80^{\circ} \mathrm{C}$ for $12 \mathrm{~h}$ to complete the reaction. Then, the mixture was cooled at room temperature and was washed with a DMF solvent. Afterward, the precipitates (washed with water and ethanol with a volume ratio of 1:1) were separated by centrifuge and dried in the oven at $80^{\circ} \mathrm{C}$ for $8 \mathrm{~h}$. To ensure the removal of any moisture and solvent, the synthesized Cu-BTC was dried at $120^{\circ} \mathrm{C}$ for $12 \mathrm{~h}$.

\subsection{Preparation of $\mathrm{Cu}$-BTC/PSf Membrane}

The PSf UF membranes were prepared by a phase-inversion method induced by immersion precipitation. Firstly, different amounts of Cu-BTC $(0.5,1,1.5,2 \%)$ based on the weight of the solution were dispersed in NMP and placed in an ultrasonic bath for $1 \mathrm{~h}$ to obtain a homogeneous suspension. Next, $16 \mathrm{wt} \%$ PSf, $2 \mathrm{wt} \%$ PEG and $1 \mathrm{wt} \%$ Triton $\mathrm{x}-100$ were added into the solution and stirred overnight to obtain a homogeneous solution. Then, the mixture was sonicated again for $60 \mathrm{~min}$ to completely eliminate the trapped air bubbles. The prepared solutions spread onto a polyester non-woven fabric attached to a clean glass plate using a home-made knife with a thickness of $100 \mu \mathrm{m}$ and instantly immersed into a coagulation bath containing distilled water and $0.1 \mathrm{wt} \%$ SDS at room temperature [37,38]. Finally, the synthesized membrane was washed repeatedly with fresh pure water to eliminate the excess solvent and then dried at ambient temperature for $24 \mathrm{~h}$. The prepared membranes were named M-0.5, M-1, M-1.5, M-2 according to the weight of Cu-BTC loaded into the casting solution.

\subsection{Characterization of $\mathrm{Cu}$-BTC MOF and Membrane}

To investigate the morphologies of Cu-BTC particles, FE-SEM images were taken at a working voltage of $5 \mathrm{kV}$. An X-ray diffraction (XRD, Philips, Amsterdam, The Netherlands) pattern of the $\mathrm{Cu}-\mathrm{BTC}$ was recorded at $298 \mathrm{~K}$ with $\mathrm{Cu}-\mathrm{Ka}$ radiation of wavelength $\lambda=1.54056^{\circ} \mathrm{A} \mathrm{K}$ for $2 \theta$ angles in the range of $5-30^{\circ}$ to further analyze the crystallinity of the MOFs. Fourier transform infrared (FTIR) spectroscopy was obtained using a FTIR spectrometer (Thermo Fisher Avatar, Waltham, MA, USA) to investigate functional groups of the Cu-BTC particles. The spectra were recorded in the 4000-400 $\mathrm{cm}^{-1}$ wavenumber with an average of $32 \mathrm{scans}$ and at a resolution of $4 \mathrm{~cm}^{-1}$. The top surface and cross-section morphologies of fabricated membranes were detected using an FE-SEM (Philips-XL30, Amsterdam, The Netherlands). All membrane samples were submerged in liquid nitrogen for a period of time and then fractured and dried at room temperature. The fractured samples were covered with a layer of gold in order to provide electric conductivity. Also, EDX analysis was applied to prove the existence and dispersion of $\mathrm{Cu}$-BTC particles in the prepared membranes. Atomic force microscopy (AFM) images were provided using nanosurf AFM (Easyscan2 Flex) to characterize the surface morphologies and also to evaluate the roughness parameters of the membranes. The roughness parameters were informed in terms of the mean roughness (Sa), the root mean square roughness (Sq) and the average of the height difference between five-points of the highest peaks and lowest valleys (Sz). The surface hydrophilicity of the synthesized membranes was determined with a goniometer (OCA 15 plus, Dataphysics) according to the sessile drop method. The contact angle measured from five different areas of each sample and the mean value was reported. The porosity $(\varepsilon \%)$ of prepared membranes were calculated by the gravimetric analyses using Equation (1) [39]:

$$
\varepsilon(\%)=\frac{\left(\mathrm{m}_{\mathrm{wet}}-\mathrm{m}_{\mathrm{dry}}\right) / \rho_{\mathrm{w}}}{\left(\mathrm{m}_{\mathrm{wet}}-\mathrm{m}_{\mathrm{dry}}\right) / \rho_{\mathrm{w}}+\left(\mathrm{m}_{\mathrm{dry}} / \rho_{\mathrm{P}}\right)} \times 100
$$


where $m_{w e t}$ and $m_{d r y}$ are the masses of the wet and dry membranes, respectively; $\rho_{\mathrm{w}}$ is the water density, $\rho_{\mathrm{p}}$ is the polymer density.

\subsection{Membrane Performance Evaluation}

The pure water flux, landfill leachate flux, and rejection of the membranes were evaluated via a cross-flow membrane module. The effective surface area of the membranes was $22 \mathrm{~cm}^{2}$ and the operating pressure of 3 bar was applied. The experiments were performed in a continuous mode at room temperature; the permeate was measured and the concentrate stream was returned to the feed tank. For all cases, the membrane flux and landfill leachate flux were calculated using Equation (2):

$$
\mathrm{J}=\frac{\mathrm{V}}{\mathrm{A} \times \Delta \mathrm{T}}
$$

where $\mathrm{V}$ is the permeate volume $(\mathrm{L}), \mathrm{A}$ is the operational membrane area $\left(\mathrm{m}^{2}\right)$, and $\mathrm{t}$ is the filtration time (h). The separation performance of each membrane was evaluated in terms of COD and NOM rejection using Equation (3):

$$
R(\%)=\left(1-\frac{C_{p}}{C_{F}}\right) \times 100
$$

where $C_{p}$ and $C_{F}$ were the contents of the permeation and feed solutions, respectively. The value of COD was determined using a spectrophotometer (Aqualytic, AL-125, ASTM D1252) and the NOM were obtained using a UV-Vis spectrophotometer (Chrom Tech, CT-2200) at $254 \mathrm{~nm}$ wavelength.

\subsection{Evaluation of Antifouling and Anti-Biofouling Properties}

Antifouling experiments were evaluated as follows: The membranes were initially compacted using distillated water for $2 \mathrm{~h}$ at a pressure of 3 bar to achieve a constant flux. The PWF $\left(\mathrm{J}_{\mathrm{pw}, 1}\right)$ was measured for $30 \mathrm{~min}$, and then LLF $\left(\mathrm{J}_{\mathrm{lfl}}\right)$ was measured for $2 \mathrm{~h}$ (the data was recorded at the interval of $10 \mathrm{~min}$ ). The fouled membranes were washed with distilled water for $30 \mathrm{~min}$ at room temperature. At the end, the PWF was measured again for $30 \mathrm{~min}$ as the $\left(\mathrm{J}_{\mathrm{pw}, 2}\right)$. The flux recovery ratio (FRR), reversible fouling ratio $\left(R_{r}\right)$, total fouling ratio $\left(R_{t}\right)$, and irreversible fouling ratio $\left(R_{\text {ir }}\right)$ were calculated with Equations (4)-(7):

$$
\begin{gathered}
\operatorname{FRR}(\%)=\frac{\mathrm{J}_{\mathrm{pw}, 2}}{\mathrm{~J}_{\mathrm{pw}, 1}} \times 100 \\
\mathrm{R}_{\mathrm{r}}(\%)=\frac{\mathrm{J}_{\mathrm{pw}, 2}-\mathrm{J}_{\mathrm{lfl}}}{\mathrm{J}_{\mathrm{pw}, 1}} \times 100 \\
\mathrm{R}_{\mathrm{ir}}(\%)=\frac{\mathrm{J}_{\mathrm{pw}, 1}-\mathrm{J}_{\mathrm{pw}, 2}}{\mathrm{~J}_{\mathrm{pw}, 1}} \times 100 \\
\mathrm{R}_{\mathrm{t}}(\%)=\frac{\mathrm{J}_{\mathrm{pw}, 1}-\mathrm{J}_{\mathrm{lfl}}}{\mathrm{J}_{\mathrm{pw}, 1}} \times 100
\end{gathered}
$$

Furthermore, the antifouling and biofouling properties of the membrane were also evaluated through the cross-flow system with $24 \mathrm{~h}$ filtration using sodium alginate and $E$. coli suspensions as fouling agents. The $\mathrm{pH}$ value of the experiment was kept constant in the range of neutral $\mathrm{pH}$ $(\sim 7)$. To further evaluate the membrane antifouling properties, a synthesized feed containing $0.2 \mathrm{mM}$ $\mathrm{NaHCO}_{3}, 0.3 \mathrm{mM} \mathrm{CaCl}, 0.4 \mathrm{mM} \mathrm{NaCl}$, and $250 \mathrm{mg} / \mathrm{L}$ sodium alginate dissolved in distilled water was applied. For the biofouling experiment, synthetic wastewater comprised of $0.61 \mathrm{mM} \mathrm{MgSO}_{4}, 0.5 \mathrm{mM}$ $\mathrm{NaHCO}_{3}, 0.45 \mathrm{mM} \mathrm{KH}_{2} \mathrm{PO}_{4}, 0.93 \mathrm{mM} \mathrm{NH}_{4} \mathrm{Cl}, 0.5 \mathrm{mM} \mathrm{CaCl}_{2}, 9.20 \mathrm{mM} \mathrm{NaCl}$ and a sufficient amount of bacteria culture at a concentration of $\sim 107 \mathrm{CFU} / \mathrm{L}$ was used $[40,41]$. After the experiments were completed, the membranes were washed under the same conditions as above, and the pure water flux 
was measured again to achieve the flux recovery ratio after $24 \mathrm{~h}$ filtration. All sections of the filtration set up were washed with alcohol before beginning the biofouling experiment.

\section{Results and Discussion}

\subsection{Characterization of the Synthetized MOFs}

Figure 1 shows the FE-SEM micrographs, FTIR and XRD results of the synthesized Cu-BTC. The FE-SEM images (Figure 1a,b) exhibited the octahedral structure of Cu-BTC with the particle size in the range of $100-500 \mathrm{~nm}$.

FTIR analysis was conducted to determine the functional groups in synthesized Cu-BTC. As shown in Figure 1c, the FTIR results are consistent with the results of Cu-BTC reported in the literature [42-44]. The wide peak around $3400 \mathrm{~cm}^{-1}$ is ascribed to the stretching vibration of $\mathrm{OH}$, and shows that the $\mathrm{Cu}$-BTC contained water molecules [43]. The peaks at 1628 and $1568 \mathrm{~cm}^{-1}$ are attributed to asymmetric stretching vibrations of the carboxylate ligands in BTC, and the peaks at 1443 and $1373 \mathrm{~cm}^{-1}$ are related to symmetric stretching vibrations of carboxylate ligands [43]. Also, the peak at $1443 \mathrm{~cm}^{-1}$ is recognized for the $\mathrm{C}-\mathrm{C}$ band in the aromatic ring [43]. The peaks at 727 and $482 \mathrm{~cm}^{-1}$ are assigned to the vibration of $\mathrm{C}-\mathrm{H}$ and $\mathrm{Cu}-\mathrm{O}$, respectively [43].

XRD analysis was carried out to evaluate the crystallinity of the $\mathrm{Cu}-\mathrm{BTC}$ and the obtained result is provided in the Figure 1d. As shown in this figure, the XRD spectrum is consistent with data reported for $\mathrm{Cu}-\mathrm{BTC}$ in the literature $[36,45,46]$. The results indicated sharp peaks at $6.88^{\circ}, 9.73^{\circ}, 11.93^{\circ}$ and $13.83^{\circ}$ that reflect (200), (220), (222) and (400) crystal planes of Cu-BTC, respectively.
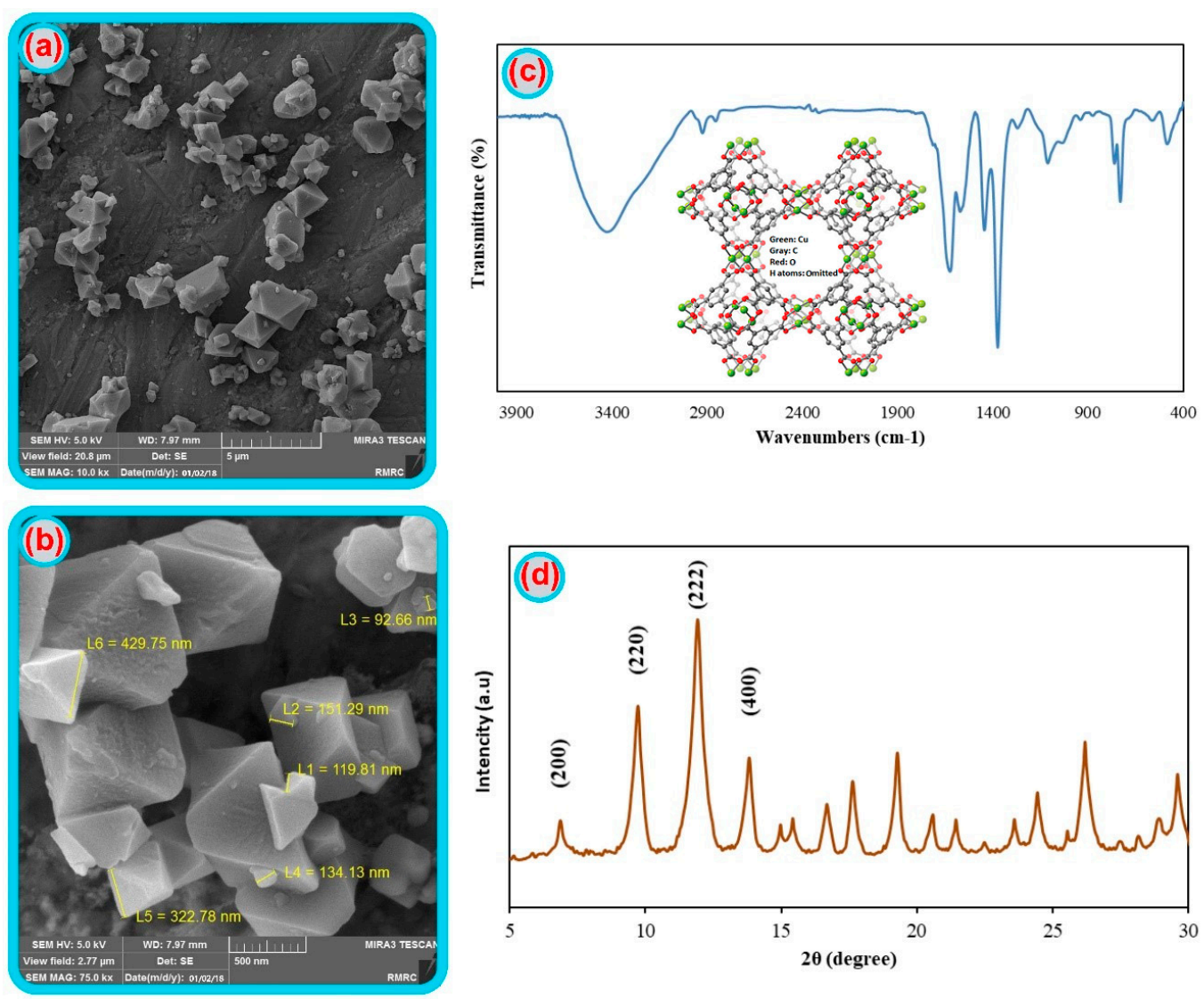

Figure 1. (a) FE-SEM images, (b) High magnification FE-SEM images, (c) FTIR spectra [47], and (d) XRD pattern of synthesized Cu-BTC. 


\subsection{Morphological Investigations of Membranes}

The cross-section and top surface FESEM images of the neat, M-1.5 and M-2 membranes are shown in Figure 2. All of the membranes showed a common asymmetric structure, comprised of a thin dense layer at the top, which is responsible for selectivity and a porous and finger-like sub-layer at the bottom, that acts as mechanical support. As can be seen, the addition of the MOF has an effect on both the surface and the sublayer, for example, the finger-like pores of modified membranes are longer and wider than the neat membrane. The good affinity of Cu-BTC particles to water media $[48,49]$ changes the kinetic and thermodynamic features of the coagulation process and speed up the exchange rate between solvent and non-solvent during the precipitation process [50,51]. Consequently, a thin skin layer at the top and porous sub-layer at the bottom with longer and wide finger-like pores were created, due to the hydrophilicity and good dispersion of Cu-BTC [52]. The high affinity of MOF particles to the water bath during phase inversion led to a particle transfer to the membrane top layer and assembled in the water-polymer interface to reduce the interfacial energy [49]. MOF particles can obviously be seen in the surface of M-2 membrane (bright point in Figure 2f).
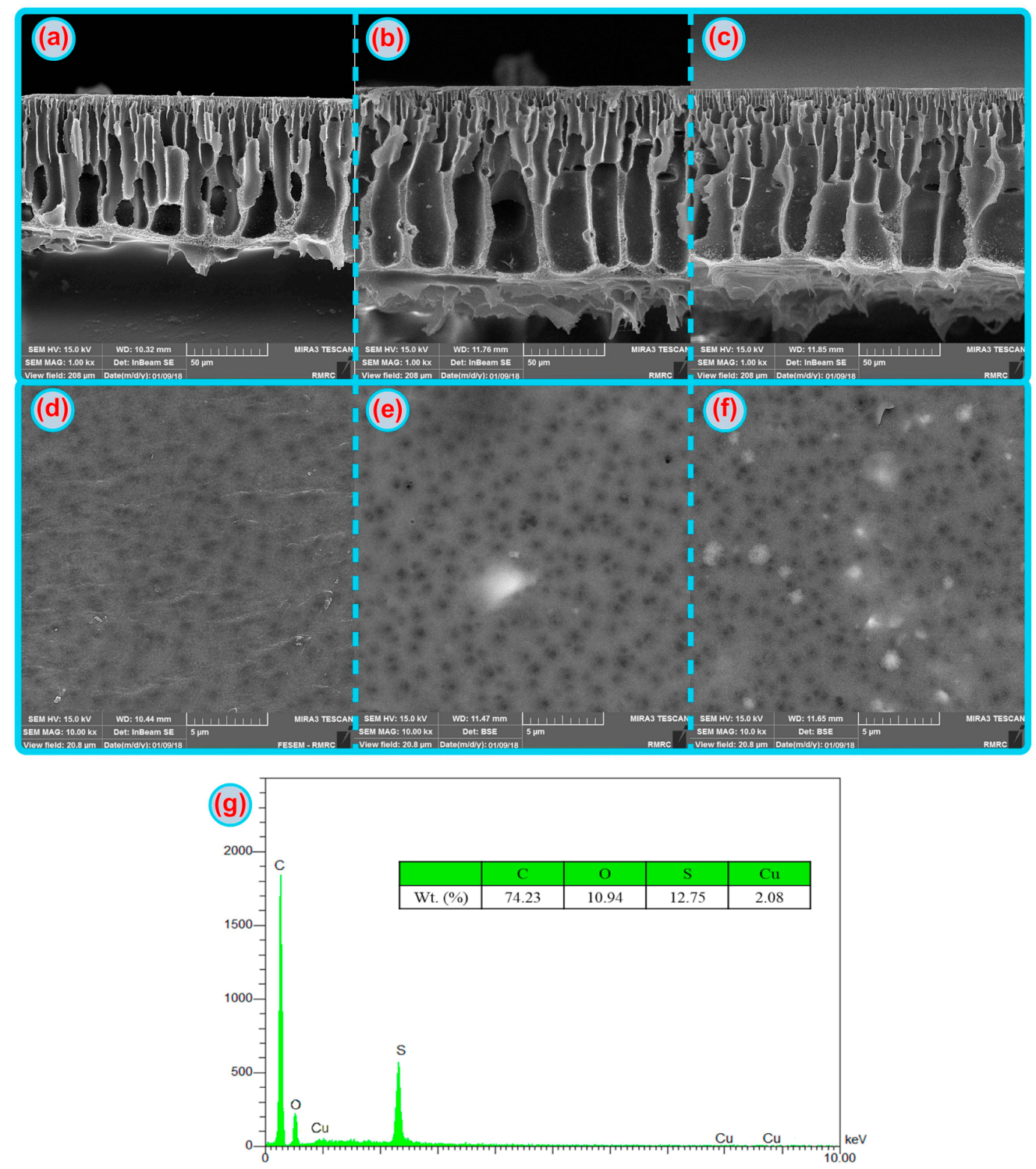

Figure 2. Cross section FE-SEM micrographs of (a) neat, (b) M-1.5, (c) M-2. Surface FE-SEM micrographs of (d) neat, (e) M-1.5, (f) M-2 and (g) EDX results of M-2 membrane. 
EDX analysis was determined to show the element composition of the M-2 membrane. The results are reported in Figure 2g. EDX analysis indicated the presence of carbon $(\mathrm{C})$, oxygen $(\mathrm{O})$, copper $(\mathrm{Cu})$ and sulfur (S). During the phase inversion, some part of the $\mathrm{Cu}-\mathrm{BTC}$ can enter into the coagulation bath, due to its hydrophilicity and the existence of the carboxylic acid group in the Cu-BTC structure, which can create some cavities in the membrane structure, but the results of the EDX analysis proved that Cu-BTC particles were well embedded in the membrane matrix.

\subsection{Hydrophilicity, Porosity, and Roughness of Membranes}

The surface contact angles of the neat and Cu-BTCs membranes are expressed in Figure 3a. In order to minimize the experimental errors, mean data from three tests were reported. It is well known that there is a reverse correlation between the contact angle and surface wettability or hydrophilicity of membranes [53,54]. As can be seen in Figure 3a, the surface contact angle of the membrane decreased by the addition of Cu-BTC, leading to improvement of the surface hydrophilicity of these modified membranes. Accordingly, the membrane surface contact angle decreased from $65.4^{\circ}$ to $56.7^{\circ}$ by the addition of $0.5 \mathrm{wt} \% \mathrm{MOF}$ in the casting solution. This might be due to the existence of hydrophilic groups (carboxylic acid) of the Cu-BTC in the membrane surface.
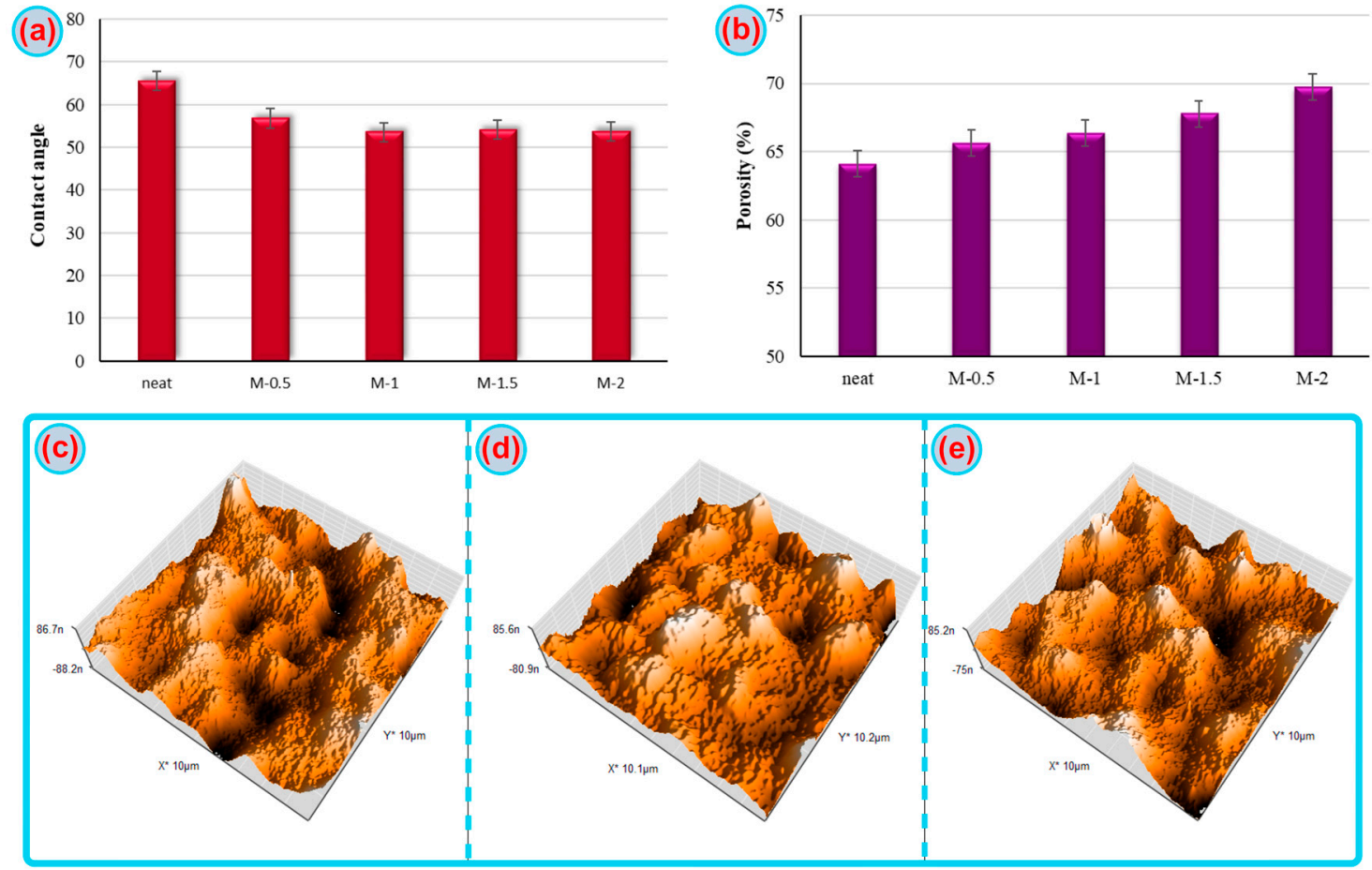

Figure 3. (a) Contact angles; (b) Porosities of the neat and Cu-BTC membranes. Three-dimensional surface AFM images of (c) neat ultrafiltration (UF), (d) M-1.5 and (e) M-2 membrane.

According to the results of porosity evaluation (Figure 3b), the overall porosity was improved with the loading of the MOF up to $2 \mathrm{wt} \%$. The porosity increment can be attributed to the influence of the MOF on the phase inversion process, which leads to the formation of a highly porous membrane. Moreover, the remaining porous $\mathrm{Cu}$ MOFs in the structure of the membranes would be another reason to increase the overall porosity of the membranes. The surface AFM images of the membranes and their roughness obtained from AFM are provided in Figure 3c-e and Table 1. As can be seen, the membrane surface roughness decreased slightly by the addition of the MOF in the polymer solution, probably due to the rapid solvent and non-solvent exchange rate during the phase inversion process [55]. The increase in roughness from the M-1.5 to the M-2 membrane may be due to the accumulation of some Cu-BTC particles on the surface of the M-2 membrane [49]. 
Table 1. Surface roughness parameters of the neat, M-1.5 and M-2 membranes.

\begin{tabular}{cccc}
\hline Membrane & $\mathbf{S}_{\mathbf{a}}(\mathbf{n m})$ & $\mathbf{S}_{\mathbf{q}}(\mathbf{n m})$ & $\mathbf{S}_{\mathbf{z}}(\mathbf{n m})$ \\
\hline neat & $27.58 \pm 2$ & $33.76 \pm 1.6$ & $217.2 \pm 5$ \\
M-1.5 & $13.85 \pm 1.4$ & $17.89 \pm 1.2$ & $123.36 \pm 4$ \\
M-2 & $24.86 \pm 1.8$ & $30.49 \pm 1.4$ & $206 \pm 5$ \\
\hline
\end{tabular}

\subsection{Membrane Performance}

In order to investigate the effect of $\mathrm{Cu}-\mathrm{BTC}$ on the membrane performance, pure water flux (PWF), landfill leachate flux (LLF), COD and NOM removals were evaluated and the results are shown in Figure $4 \mathrm{a}, \mathrm{b}$. All tests were repeated three times and the mean data reported. It can be found that the PWF and LLF of the modified membranes were improved by MOF loading. Adding the hydrophilic MOF to the casting solution would increase the rate of water penetration into the polymer solution during the phase inversion process. Conversely, the existence of the MOF reduces the thermodynamic stability of the casting solution, interrupts the polymer chains and decreases the interaction between the solvent and the polymer chains, resulting in an increase in the solvent exhaust. Both of these phenomena increase the exchange rate between the solvent and non-solvent, precipitation takes place faster and therefore leads to a more porous structure membrane [56]. Also, the hydrophilic surface of the membrane and highly porous structure of $\mathrm{Cu}$-BTC may absorb water molecules and create an additional crossing path for water through the membrane [57]. All of these causes higher PWF for MOF modified membranes than the neat membrane (Figure 4a). As can be seen, the M-2 membrane showed approximately $70 \%$ increase in PWF and 50\% increase in LLF, as compared to the neat membrane (Figure 4a,b).
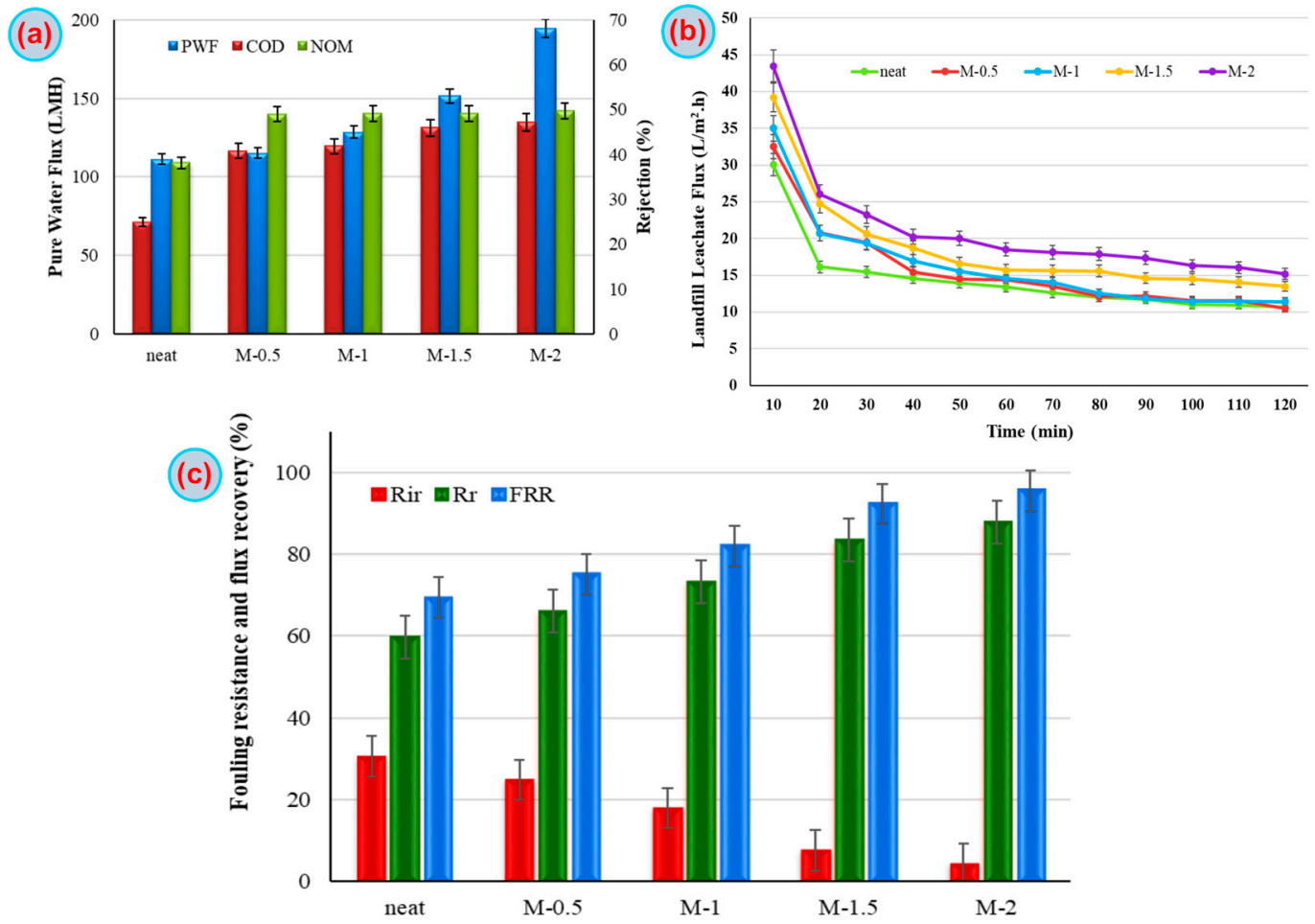

Figure 4. (a) Pure water flux and rejection coefficients; (b) Landfill leachate flux; (c) Flux recovery ratios (FRRs) and fouling resistances of the neat and $\mathrm{Cu}-\mathrm{BTC}$ membranes.

The rapid decline of the landfill leachate flux in the first stage is due to the pore blockage by the foulant, and in the second stage it is due to the deposit of the cake layer on the surface [58]. Thus, 
a decrease of flux can be attributed to the accumulation of foulants on the surface and pores and finally, the flux reached a steady constant during filtration.

The compatibility of the fillers and polymer is an effective parameter in the selectivity of the membrane [55]. Due to the presence of organic linkers in the MOF structure, they show a good tendency to adhere to the polymer and result in preventing the formation of non-selective voids in the membrane structure. Accordingly, MOF modified membranes showed better rejection than the neat membrane. As can be seen in Figure 4a, the rejection results from LLF experiments showed that the neat membrane reduces the COD only to $24 \%$, but with the addition of $0.5 \mathrm{wt} \% \mathrm{Cu}$-BTC, the COD removal enhanced about $66 \%$ (from $24 \%$ to $40 \%$ ) of the neat membrane. Additionally, the formation of smaller pore sizes in the presence of MOF during the phase inversion process is another reason for better rejection of the modified membrane.

\subsection{Membrane Antifouling Performance}

For the evaluation of antifouling properties of modified membranes, the flux recovery ratio (FRR), reversible resistance (Rr) and irreversible resistance (Rir) were measured and displayed in Figure 4c. The fouled membranes were washed only with pure water for $30 \mathrm{~min}$ after the landfill leachate filtration was completed. As shown in Figure 4c, the addition of $2 \mathrm{wt} \%$ MOF led to an improvement in the FRR, from $69 \%$ of the neat membrane to more than $90 \%$ of the modified membrane, showing weak adsorption between the foulant of the feed solution and the surface of the modified membranes. Moreover, by increasing the $\mathrm{Cu}-\mathrm{BTC}$ content, the irreversible fouling of the modified membranes decreases. Figure $4 \mathrm{c}$ shows a $26 \%$ decrease (from $30 \%$ to $4 \%$ ) for the M-2 membrane. It can be found that Cu-BTC improved the cleanability of the modified membranes.The existence of hydrophilic groups on the surface and pores of MOF membranes formed hydrated layers on the surface and decreased the hydrophobic interaction among the membrane surface and organic foulants [59]. Moreover, according to the AFM results, the smoother surface may have a good effect in developing antifouling properties of the membrane surface, because of the smaller surface area in contact with the foulants [60].

To further evaluate the antifouling properties of membranes, the organic fouling and bio-fouling behavior of neat membrane and $2 \mathrm{wt} \%$ MOF modified membrane were evaluated with sodium alginate and E. coli suspensions, respectively, as shown in Figure 5. The reported data are the average of two runs. The results from filtration of sodium alginate solution confirmed that the MOF modified membrane (M-2) demonstrated better antifouling properties than the neat membrane. This membrane showed a flux decline of approximately $42 \%$, while the neat membrane indicated a high flux decline of approximately $75 \%$ after $24 \mathrm{~h}$ filtration. The results indicate that the membrane with Cu-BTC had a suitable flux recovery ratio, with a lower water flux reduction, due to its higher surface hydrophilicity. For long-term experiments, the flux recovery ratios were $67 \%$ and $90 \%$ for the neat and M-2 membranes, respectively, indicating good antifouling properties for the MOF modified membranes.

Similar results were also observed in the filtration of the $E$. coli suspension. The M-2 membrane showed a flux decline of approximately $40 \%$, while the neat membrane indicated a high flux decline of approximately $70 \%$ after $24 \mathrm{~h}$ filtration, again. The MOF membrane exhibited improved anti-biofouling properties, due to its higher surface wettability and strong antibacterial properties of Cu-BTC reported in our previous research [40]. The flux recovery ratios were $52 \%$ and $88 \%$ for the neat and M-2 membranes, respectively.

Copper has been identified as having antimicrobial properties [61] and is used in different forms (nanoparticle, ion, etc.) for modification of the membrane,in order to improve its antibacterial properties [62-64]. The properties of Cu-BTC MOF against bacteria come from $\mathrm{Cu}$ ions in their structure that are attached to the organic linker with chemical bonds [65]. A sustained antibacterial activity can be provided by $\mathrm{Cu}$-BTC MOFs, namely the reservoir of copper $\left(\mathrm{Cu}^{2+}\right)$ ions [66]. The main antibacterial mechanism of the MOFs is the long-lasting metal ion release [67]. The metal active sites in the MOFs are uniformity distributed and the mechanism of metal release does not change through degradation of the material. Additionally, the organic linker applied for fabrication of the framework might itself have 
antimicrobial activity and hence, a synergistic effect may be achieved [49]. The proposed antibacterial mechanism includes cell wall rupture and plasma membrane deterioration through contact with the $\mathrm{Cu}^{2+}$ metal sites, which can oxidize organic species. The equal distribution of metal ions in the MOF structure prevents metal agglomeration and blocking the active sites of copper [66]. Also, good compatibility of the organic linker in the MOF structure with polymer makes good dispersion of MOF in the membrane matrix and prevent formation voids between two phases. All of these factors make for better anti-biofouling properties of the MOF membrane against a bacteria solution, than the neat membrane.

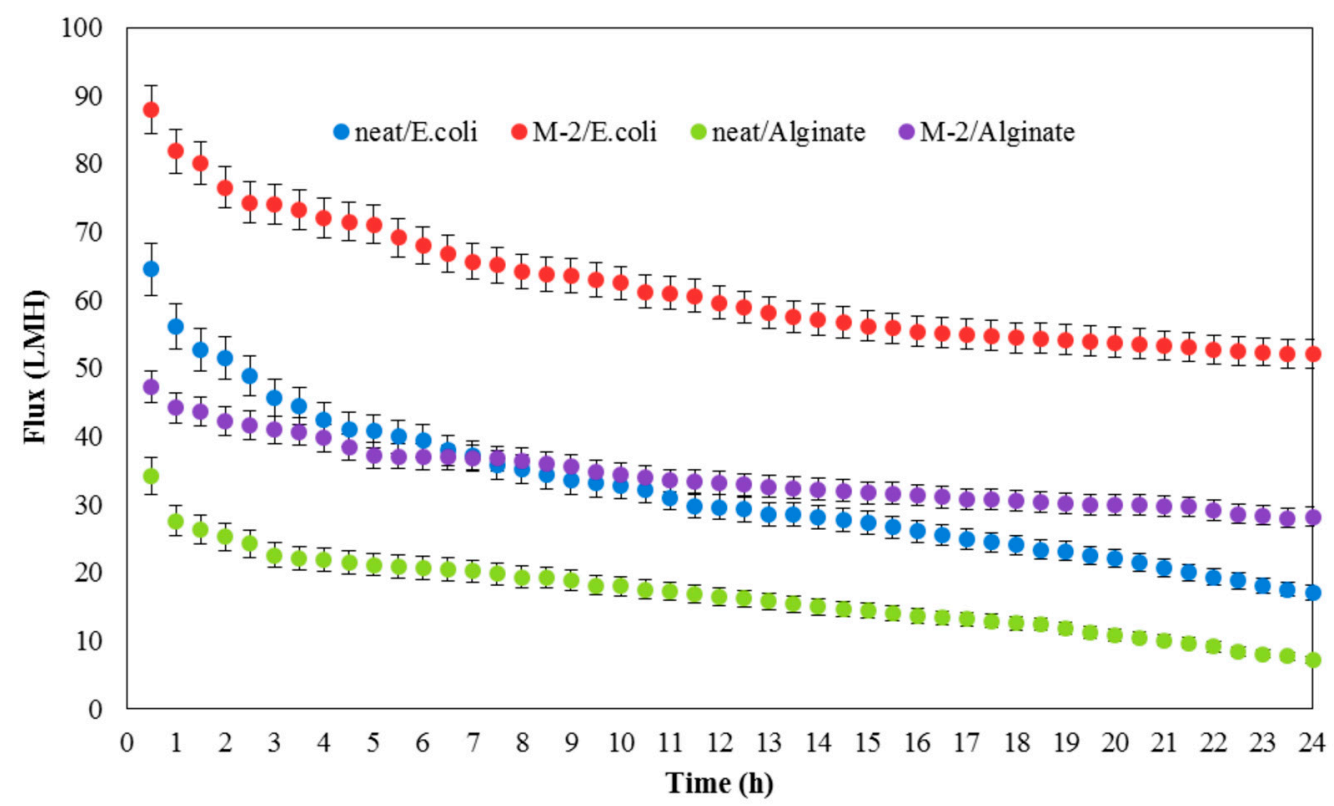

Figure 5. Fouling performance of the neat and M-2 membranes with the organic foulant and bio-foulant.

\section{Conclusions}

In this study, Cu-BTC MOFs were first synthesized through ultrasonic followed by the reflux method and then used as an additive to modify the polysulfone ultrafiltration membrane through phase inversion technique. The existence of the Cu-BTC MOF in the structure of prepared membranes is confirmed by EDX analysis. The modified membranes showed a lower contact angle than the neat membrane, demonstrating the more hydrophilic surface because of the existence of carboxyl groups on the surface. Furthermore, modified membranes showed improved pure water and landfill leachate flux without reducing the rejection due to a more porous structure. The highest water flux of $194 \mathrm{LMH}$ was observed for the M-2 membrane, which also showed 50\% higher landfill leachate flux compared to the neat membrane. Moreover, by addition of only $0.5 \mathrm{wt} \% \mathrm{Cu}$-BTC into the casting solution, the COD rejection increased up to $66 \%$, as compared to the neat membrane. Additionally the antifouling and anti-biofouling behavior of the membranes were investigated using sodium alginate and E. coli suspensions as fouling agents, and the obtained results indicated better antifouling and anti-biofouling properties for $\mathrm{Cu}-\mathrm{MOF}$ modified membranes.

Author Contributions: Conceptualization, M.M., and S.A.A.; investigation, M.M. and S.A.A.; data curation, M.M.; writing—original draft preparation, M.M.; writing—review and editing, M.M., S.A.A., A.R. and N.T.H.K.; supervision, A.R. and N.T.H.K.; project administration, A.R. All authors have read and agreed to the published version of the manuscript.

Funding: This research received no external funding.

Conflicts of Interest: The authors declare no conflict of interest. 


\section{References}

1. Esfahani, M.R.; Aktij, S.A.; Dabaghian, Z.; Firouzjaei, M.D.; Rahimpour, A.; Eke, J.; Escobar, I.C.; Abolhassani, M.; Greenlee, L.F.; Esfahani, A.R. Nanocomposite membranes for water separation and purification: Fabrication, modification, and applications. Sep. Purif. Technol. 2018, 213, 465-499. [CrossRef]

2. Fane, A.G.; Wang, R.; Hu, M.X. Synthetic membranes for water purification: Status and future. Angew. Chem. Int. Ed. 2015, 54, 3368-3386. [CrossRef] [PubMed]

3. Ahmad, A.; Abdulkarim, A.; Ooi, B.; Ismail, S. Recent development in additives modifications of polyethersulfone membrane for flux enhancement. Chem. Eng. J. 2013, 223, 246-267. [CrossRef]

4. Rahimpour, A.; Seyedpour, S.F.; Aktij, S.A.; Firouzjaei, M.D.; Zirehpour, A.; Shamsabadi, A.A.; Salestan, S.K.; Jabbari, M.; Soroush, M. Simultaneous improvement of antimicrobial, antifouling, and transport properties of forward osmosis membranes with immobilized highly-compatible polyrhodanine nanoparticles. Environ. Sci. Technol. 2018, 52, 5246-5258. [CrossRef] [PubMed]

5. Firouzjaei, M.D.; Seyedpour, S.F.; Aktij, S.A.; Giagnorio, M.; Bazrafshan, N.; Mollahosseini, A.; Samadi, F.; Ahmadalipour, S.; Firouzjaei, F.D.; Esfahani, M.R.; et al. Recent advances in functionalized polymer membranes for biofouling control and mitigation in forward osmosis. J. Membr. Sci. 2019. [CrossRef]

6. Coppini, E.; Palli, L.; Fibbi, D.; Gori, R. Long-Term performance of a full-scale membrane plant for landfill leachate pretreatment: A case study. Membranes 2018, 8, 52. [CrossRef]

7. Aktij, S.A.; Zirehpour, A.; Mollahosseini, A.; Taherzadeh, M.J.; Tiraferri, A.; Rahimpour, A. Feasibility of Membrane Processes for the Recovery and Purification of Bio-Based Volatile Fatty Acids: A Comprehensive Review. J. Ind. Eng. Chem. 2019, 81, 24-40. [CrossRef]

8. Gao, W.; Liang, H.; Ma, J.; Han, M.; Chen, Z.-L.; Han, Z.-S.; Li, G.-B. Membrane fouling control in ultrafiltration technology for drinking water production: A review. Desalination 2011, 272, 1-8. [CrossRef]

9. Zirehpour, A.; Rahimpour, A.; Jahanshahi, M.; Peyravi, M. Mixed matrix membrane application for olive oil wastewater treatment: Process optimization based on Taguchi design method. J. Environ. Manag. 2014, 132, 113-120. [CrossRef]

10. Madaeni, S.; Hasankiadeh, N.T.; Kurdian, A.; Rahimpour, A. Modeling and optimization of membrane fabrication using artificial neural network and genetic algorithm. Sep. Purif. Technol. 2010, 76, 33-43. [CrossRef]

11. Han, J.; Lee, W.; Choi, J.M.; Patel, R.; Min, B.-R. Characterization of polyethersulfone/polyimide blend membranes prepared by a dry/wet phase inversion: Precipitation kinetics, morphology and gas separation. J. Membr. Sci. 2010, 351, 141-148. [CrossRef]

12. Lee, S.-J.; Dilaver, M.; Park, P.-K.; Kim, J.-H. Comparative analysis of fouling characteristics of ceramic and polymeric microfiltration membranes using filtration models. J. Membr. Sci. 2013, 432, 97-105. [CrossRef]

13. Yang, L.; Tang, B.; Wu, P. UF membrane with highly improved flux by hydrophilic network between graphene oxide and brominated poly (2, 6-dimethyl-1, 4-phenylene oxide). J. Mater. Chem. A 2014, 2, 18562-18573. [CrossRef]

14. Esfahani, M.R.; Koutahzadeh, N.; Esfahani, A.R.; Firouzjaei, M.D.; Anderson, B.; Peck, L. A novel gold nanocomposite membrane with enhanced permeation, rejection and self-cleaning ability. J. Membr. Sci. 2019, 573, 309-319. [CrossRef]

15. Yang, Y.; Zhang, H.; Wang, P.; Zheng, Q.; Li, J. The influence of nano-sized TiO2 fillers on the morphologies and properties of PSF UF membrane. J. Membr. Sci. 2007, 288, 231-238. [CrossRef]

16. Razmjou, A.; Mansouri, J.; Chen, V. The effects of mechanical and chemical modification of TiO2 nanoparticles on the surface chemistry, structure and fouling performance of PES ultrafiltration membranes. J. Membr. Sci. 2011, 378, 73-84. [CrossRef]

17. Pourjafar, S.; Jahanshahi, M.; Rahimpour, A. Optimization of TiO2 modified poly (vinyl alcohol) thin film composite nanofiltration membranes using Taguchi method. Desalination 2013, 315, 107-114. [CrossRef]

18. Shen, J.-N.; Ruan, H.-M.; Wu, L.-G.; Gao, C.-J. Preparation and characterization of PES-SiO2 organic-inorganic composite ultrafiltration membrane for raw water pretreatment. Chem. Eng. J. 2011, 168, 1272-1278. [CrossRef]

19. Ahmad, A.; Majid, M.; Ooi, B. Functionalized PSf/SiO2 nanocomposite membrane for oil-in-water emulsion separation. Desalination 2011, 268, 266-269. [CrossRef]

20. Ayyaru, S.; Ahn, Y.-H. Application of sulfonic acid group functionalized graphene oxide to improve hydrophilicity, permeability, and antifouling of PVDF nanocomposite ultrafiltration membranes. J. Membr. Sci. 2017, 525, 210-219. [CrossRef] 
21. Zhao, C.; Xu, X.; Chen, J.; Yang, F. Effect of graphene oxide concentration on the morphologies and antifouling properties of PVDF ultrafiltration membranes. J. Environ. Chem. Eng. 2013, 1, 349-354. [CrossRef]

22. Rowsell, J.L.; Yaghi, O.M. Metal-organic frameworks: A new class of porous materials. Microporous Mesoporous Mater. 2004, 73, 3-14. [CrossRef]

23. Firouzjaei, M.D.; Shamsabadi, A.A.; Aktij, S.A.; Seyedpour, S.F.; Sharifian Gh, M.; Rahimpour, A.; Esfahani, M.R.; Ulbricht, M.; Soroush, M. Exploiting synergetic effects of graphene oxide and a silver-based metal-organic framework to enhance antifouling and anti-biofouling properties of thin-film nanocomposite membranes. ACS Appl. Mater. Interfaces 2018, 10, 42967-42978. [CrossRef] [PubMed]

24. Elrasheedy, A.; Nady, N.; Bassyouni, M.; El-Shazly, A. Metal organic framework based polymer mixed matrix membranes: Review on applications in water purification. Membranes 2019, 9, 88. [CrossRef] [PubMed]

25. Firouzjaei, M.D.; Shamsabadi, A.A.; Sharifian-Gh, M.; Rahimpour, A.; Soroush, M. A novel nanocomposite with superior antibacterial activity: A silver-based metal organic framework embellished with graphene oxide. Adv. Mater. Interfaces 2018, 5, 1701365. [CrossRef]

26. Lu, C.; Wang, G.; Wang, K.; Guo, D.; Bai, M.; Wang, Y. Modified Porous SiO2-Supported Cu3 (BTC) 2 Membrane with High Performance of Gas Separation. Materials 2018, 11, 1207. [CrossRef]

27. Luo, X.; Ding, L.; Luo, J. Adsorptive removal of $\mathrm{Pb}$ (II) ions from aqueous samples with amino-functionalization of metal-organic frameworks MIL-101 (Cr). J. Chem. Eng. Data 2015, 60, 1732-1743. [CrossRef]

28. Wang, C.; Liu, X.; Chen, J.P.; Li, K. Superior removal of arsenic from water with zirconium metal-organic framework UiO-66. Sci. Rep. 2015, 5, 16613. [CrossRef]

29. Ragab, D.; Gomaa, H.; Sabouni, R.; Salem, M.; Ren, M.; Zhu, J. Micropollutants removal from water using microfiltration membrane modified with ZIF-8 metal organic frameworks (MOFs). Chem. Eng. J. 2016, 300, 273-279. [CrossRef]

30. Qiu, S.; Xue, M.; Zhu, G. Metal-organic framework membranes: From synthesis to separation application. Chem. Soc. Rev. 2014, 43, 6116-6140. [CrossRef]

31. Kebria, M.R.S.; Rahimpour, A.; Bakeri, G.; Abedini, R. Experimental and theoretical investigation of thin ZIF-8/chitosan coated layer on air gap membrane distillation performance of PVDF membrane. Desalination 2019, 450, 21-32. [CrossRef]

32. Ge, B.; Xu, Y.; Zhao, H.; Sun, H.; Guo, Y.; Wang, W. High performance gas separation mixed matrix membrane fabricated by incorporation of functionalized submicrometer-sized metal-organic framework. Materials 2018, 11, 1421. [CrossRef] [PubMed]

33. Van der Bruggen, B. Chemical modification of polyethersulfone nanofiltration membranes: A review. J. Appl. Polym. Sci. 2009, 114, 630-642. [CrossRef]

34. Prince, J.; Bhuvana, S.; Anbharasi, V.; Ayyanar, N.; Boodhoo, K.; Singh, G. Self-cleaning Metal Organic Framework (MOF) based ultra filtration membranes-A solution to bio-fouling in membrane separation processes. Sci. Rep. 2014, 4, 6555. [CrossRef] [PubMed]

35. Sotto, A.; Orcajo, G.; Arsuaga, J.M.; Calleja, G.; Landaburu-Aguirre, J. Preparation and characterization of MOF-PES ultrafiltration membranes. J. Appl. Polym. Sci. 2015, 132. [CrossRef]

36. Khoshhal, S.; Ghoreyshi, A.A.; Jahanshahi, M.; Mohammadi, M. Study of the temperature and solvent content effects on the structure of $\mathrm{Cu}-\mathrm{BTC}$ metal organic framework for hydrogen storage. RSC Adv. 2015, 5, 24758-24768. [CrossRef]

37. Alsari, A.M.; Khulbe, K.; Matsuura, T. The effect of sodium dodecyl sulfate solutions as gelation media on the formation of PES membranes. J. Membr. Sci. 2001, 188, 279-293. [CrossRef]

38. Mokhtari, S.; Rahimpour, A.; Shamsabadi, A.A.; Habibzadeh, S.; Soroush, M. Enhancing performance and surface antifouling properties of polysulfone ultrafiltration membranes with salicylate-alumoxane nanoparticles. Appl. Surf. Sci. 2017, 393, 93-102. [CrossRef]

39. Feng, C.; Wang, R.; Shi, B.; Li, G.; Wu, Y. Factors affecting pore structure and performance of poly (vinylidene fluoride-co-hexafluoro propylene) asymmetric porous membrane. J. Membr. Sci. 2006, 277, 55-64. [CrossRef]

40. Mozafari, M.; Seyedpour, S.F.; Salestan, S.K.; Rahimpour, A.; Shamsabadi, A.A.; Firouzjaei, M.D.; Esfahani, M.R.; Tiraferri, A.; Mohsenian, H.; Sangermano, M. Facile Cu-BTC surface modification of thin chitosan film coated polyethersulfone membranes with improved antifouling properties for sustainable removal of manganese. J. Membr. Sci. 2019, 588, 117200. [CrossRef] 
41. Seyedpour, S.F.; Rahimpour, A.; Najafpour, G. Facile in-situ assembly of silver-based MOFs to surface functionalization of TFC membrane: A novel approach toward long-lasting biofouling mitigation. J. Membr. Sci. 2019, 573, 257-269. [CrossRef]

42. Sani, N.; Lau, W.; Ismail, A. Polyphenylsulfone-based solvent resistant nanofiltration (SRNF) membrane incorporated with copper-1, 3, 5-benzenetricarboxylate (Cu-BTC) nanoparticles for methanol separation. RSC Adv. 2015, 5, 13000-13010. [CrossRef]

43. Wang, Y.; Wu, Y.; Xie, J.; Ge, H.; Hu, X. Multi-walled carbon nanotubes and metal-organic framework nanocomposites as novel hybrid electrode materials for the determination of nano-molar levels of lead in a lab-on-valve format. Analyst 2013, 138, 5113-5120. [CrossRef] [PubMed]

44. Wang, F.; Guo, H.; Chai, Y.; Li, Y.; Liu, C. The controlled regulation of morphology and size of HKUST-1 by "coordination modulation method". Microporous Mesoporous Mater. 2013, 173, 181-188. [CrossRef]

45. Lin, K.-S.; Adhikari, A.K.; Ku, C.-N.; Chiang, C.-L.; Kuo, H. Synthesis and characterization of porous HKUST-1 metal organic frameworks for hydrogen storage. Int. J. Hydrogen Energy 2012, 37, 13865-13871. [CrossRef]

46. Li, Z.-Q.; Qiu, L.-G.; Xu, T.; Wu, Y.; Wang, W.; Wu, Z.-Y.; Jiang, X. Ultrasonic synthesis of the microporous metal-organic framework Cu3 (BTC) 2 at ambient temperature and pressure: An efficient and environmentally friendly method. Mater. Lett. 2009, 63, 78-80. [CrossRef]

47. Zukal, A.; Opanasenko, M.; Rubeš, M.; Nachtigall, P.; Jagiello, J. Adsorption of pentane isomers on metal-organic frameworks Cu-BTC and Fe-BTC. Catal. Today 2015, 243, 69-75. [CrossRef]

48. Küsgens, P.; Rose, M.; Senkovska, I.; Fröde, H.; Henschel, A.; Siegle, S.; Kaskel, S. Characterization of metal-organic frameworks by water adsorption. Microporous Mesoporous Mater. 2009, 120, 325-330. [CrossRef]

49. Zirehpour, A.; Rahimpour, A.; Khoshhal, S.; Firouzjaei, M.D.; Ghoreyshi, A.A. The impact of MOF feasibility to improve the desalination performance and antifouling properties of FO membranes. RSC Adv. 2016, 6, 70174-70185. [CrossRef]

50. Ma, Y.; Shi, F.; Ma, J.; Wu, M.; Zhang, J.; Gao, C. Effect of PEG additive on the morphology and performance of polysulfone ultrafiltration membranes. Desalination 2011, 272, 51-58. [CrossRef]

51. Guillen, G.R.; Pan, Y.; Li, M.; Hoek, E.M. Preparation and characterization of membranes formed by nonsolvent induced phase separation: A review. Ind. Eng. Chem. Res. 2011, 50, 3798-3817. [CrossRef]

52. Mollahosseini, A.; Rahimpour, A.; Jahamshahi, M.; Peyravi, M.; Khavarpour, M. The effect of silver nanoparticle size on performance and antibacteriality of polysulfone ultrafiltration membrane. Desalination 2012, 306, 41-50. [CrossRef]

53. Nabe, A.; Staude, E.; Belfort, G. Surface modification of polysulfone ultrafiltration membranes and fouling by BSA solutions. J. Membr. Sci. 1997, 133, 57-72. [CrossRef]

54. Aktij, S.A.; Rahimpour, A.; Figoli, A. Low content nano-polyrhodanine modified polysulfone membranes with superior properties and their performance for wastewater treatment. Environ. Sci. Nano 2017, 4, 2043-2054. [CrossRef]

55. Sun, H.; Tang, B.; Wu, P. Development of hybrid ultrafiltration membranes with improved water separation properties using modified superhydrophilic metal-organic framework nanoparticles. ACS Appl. Mater. Interfaces 2017, 9, 21473-21484. [CrossRef] [PubMed]

56. Reuvers, A.; Smolders, C. Formation of membranes by means of immersion precipitation: Part II. the mechanism of formation of membranes prepared from the system cellulose acetate-acetone-water. J. Membr. Sci. 1987, 34, 67-86. [CrossRef]

57. Zirehpour, A.; Rahimpour, A.; Arabi Shamsabadi, A.; Sharifian-Gh, M.; Soroush, M. Mitigation of thin-film composite membrane biofouling via immobilizing nano-sized biocidal reservoirs in the membrane active layer. Environ. Sci. Technol. 2017, 51, 5511-5522. [CrossRef]

58. Huang, J.; Zhang, K.; Wang, K.; Xie, Z.; Ladewig, B.; Wang, H. Fabrication of polyethersulfone-mesoporous silica nanocomposite ultrafiltration membranes with antifouling properties. J. Membr. Sci. 2012, 423, 362-370. [CrossRef]

59. Arsuaga, J.M.; Sotto, A.; del Rosario, G.; Martínez, A.; Molina, S.; Teli, S.B.; de Abajo, J. Influence of the type, size, and distribution of metal oxide particles on the properties of nanocomposite ultrafiltration membranes. J. Membr. Sci. 2013, 428, 131-141. [CrossRef]

60. Vrijenhoek, E.M.; Hong, S.; Elimelech, M. Influence of membrane surface properties on initial rate of colloidal fouling of reverse osmosis and nanofiltration membranes. J. Membr. Sci. 2001, 188, 115-128. [CrossRef] 
61. Casey, A.; Adams, D.; Karpanen, T.; Lambert, P.; Cookson, B.; Nightingale, P.; Miruszenko, L.; Shillam, R.; Christian, P.; Elliott, T. Role of copper in reducing hospital environment contamination. J. Hosp. Infect. 2010, 74, 72-77. [CrossRef] [PubMed]

62. Akar, N.; Asar, B.; Dizge, N.; Koyuncu, I. Investigation of characterization and biofouling properties of PES membrane containing selenium and copper nanoparticles. J. Membr. Sci. 2013, 437, 216-226. [CrossRef]

63. Zhang, J.; Xu, Y.; Chen, S.; Li, J.; Han, W.; Sun, X.; Wu, D.; Hu, Z.; Wang, L. Enhanced antifouling and antibacterial properties of poly (ether sulfone) membrane modified through blending with sulfonated poly (aryl ether sulfone) and copper nanoparticles. Appl. Surf. Sci. 2018, 434, 806-815. [CrossRef]

64. Chen, Y.; Zhang, Y.; Liu, J.; Zhang, H.; Wang, K. Preparation and antibacterial property of polyethersulfone ultrafiltration hybrid membrane containing halloysite nanotubes loaded with copper ions. Chem. Eng. J. 2012, 210, 298-308. [CrossRef]

65. Rodríguez, H.S.; Hinestroza, J.P.; Ochoa-Puentes, C.; Sierra, C.A.; Soto, C.Y. Antibacterial activity against Escherichia coli of Cu-BTC (MOF-199) metal-organic framework immobilized onto cellulosic fibers. J. Appl. Polym. Sci. 2014, 131. [CrossRef]

66. Wyszogrodzka, G.; Marszałek, B.; Gil, B.; Dorożyński, P. Metal-organic frameworks: Mechanisms of antibacterial action and potential applications. Drug Discov. Today 2016, 21, 1009-1018. [CrossRef]

67. Mozafari, M.S.; Seyedpour, F.; Salestan, S.K.; Rahimpour, A.; Shamsabadi, A.A.; Firouzjaei, M.D.; Esfahani, M.R.; Tiraferri, A.; Mohsenian, H.; Marco Sangermano, M.; et al. Facile Cu-BTC surface modification of thin chitosan film coated polyethersulfone membranes with improved antifouling properties for sustainable removal of manganese. J. Membr. Sci. 2019, 588, 117200. [CrossRef]

(C) 2019 by the authors. Licensee MDPI, Basel, Switzerland. This article is an open access article distributed under the terms and conditions of the Creative Commons Attribution (CC BY) license (http://creativecommons.org/licenses/by/4.0/). 